\title{
Functional outcome of wound coverage of soft tissue defects over ankle and foot
}

\author{
Arjun Naik ${ }^{1, *}$, Edward Nazareth ${ }^{2}$, Latheesh Leo ${ }^{3}$ \\ ${ }^{1}$ Resident, ${ }^{2}$ Professor, ${ }^{3}$ Associate Professor, Dept. of Orthopaedics, Father Muller Medical College, Mangaluru, Karnataka, India \\ *Corresponding Author: \\ Email: drarjunnaik@gmail.com
}

\begin{abstract}
Introduction: Open fractures around the ankle and foot are complex injuries which can lead to wound complications or amputations. Based on the location, soft tissue loss is treated with different varieties of flaps. The focus has shifted to the ideal tissue for wound coverage. The aim of this study was to evaluate the functional outcome at the end of 6 months and 12 months, correlation of Mangled extremity severity score to the functional outcome and the factors that cause flap failure.

Materials and Methods: Totally 32 patients (30 male, 2 female) presenting with type IIIB Gustillo-Anderson fracture over ankle and foot from October 2014 to October 2015 were followed up for a period of 12 months following open reduction, internal fixation and wound coverage with free flaps or local flaps. The mean age was 35.12 years (range: 5 years to 75 years). The patients were evaluated for Mangled extremity severity score(MESS), time period for wound coverage, failures and its cause along with foot and ankle orthopaedic society(FAOS) scores at 6 and 12 months.

Results: Functional outcome following wound coverage significantly improved over 12 months which was inversely proportional to the mangled extremity severity score. On comparison of FAOS at 6 months and 12 months using Wilcoxon signed rank test for non-parametric data, $\mathrm{p}$ value was $<0.001$ which meant outcomes were significantly good for pain, symptoms, activity of daily living, sports and quality of life. However, we found no difference in outcome when comparing the same parameters with different methods of wound coverage. Venous congestion of a free flap has to be carefully monitored.

Conclusion: In this study we conclude that specialized and early wound debridement, fracture reduction and soft tissue coverage (within 3 days) in the hands of an experienced surgeon gives the best functional outcome in type IIIB open fractures of ankle and foot. However, Mangled extremity severity score (MESS) is a good predictor of the outcome of the patient. The functional outcome using foot and ankle orthopaedic score has shown significant improvement from 6 months to 12 months. Selection of the flap depends on the surgeon preference and anatomical location of the wound. Patient factors like age and gender showed no difference in outcome. Early rehabilitation has a direct influence on the functional outcome of the ankle and foot movements.
\end{abstract}

Keywords: Flaps, Microvascular techniques, MESS, Limb salvage.

\section{Introduction}

The problems involved with open injuries to distal tibia, ankle and foot has always concerned the orthopaedic surgeon because of poor soft tissue coverage leading to difficulty in closure and healing complications. Many a times open fractures with skin defects over ankle and foot ended in amputations. The financial burden and economic impact to the patient and his family has lead to detailed studies on management of open fractures of ankle and foot. Over a period of time classifications have been applied to decide on which limb can be salvaged and this has changed the face of trauma management and limb reconstructive surgery as most of the limbs which would have been amputated could now be saved. Progress in the field of microvascular surgery by free muscle flaps and local flaps has improved the chances of limb salvage. The functional outcome of advanced wound coverage over ankle and foot was a concern as a cosmetically acceptable but non-functional foot served no good to the patient and was an added burden to his daily living. This initiated our study to determine the functional outcome of the different types of wound coverage and its correlation to Mangled extremity severity score (MESS) at 6 months and 12 months along with factors leading to complications or poor outcome.

\section{Materials and Methods}

Patients who underwent wound coverage over ankle and foot using local and free flaps in Father Muller medical college hospital were evaluated using foot and ankle orthopedic score and Mangled extremity severity score.

A total of 34 patients in the age group of 5 years- 75 years with Gustillo-Anderson type IIIB fracture in the ankle or foot with flap coverage carried out within a week of trauma were included in the study out of which 2 were excluded due to failure to follow up. Among the included patients 3 patients underwent latissmus dorsi flap, 9 patients underwent antero-lateral thigh flap, 11 patients underwent peroneus brevis flap, 2 underwent gracillis flap, 5 underwent reverse sural artery flap and 1 patient each underwent abductor digiti minimi flap, propeller flap and cross leg flap. Patients with previous deformity in the lower limb were excluded from the study.

Surgical procedure was carried out after confirmation of diagnosis by clinical and radiological examination. Limb was immobilized using plaster of Paris slab depending on the site of wound. Wound was inspected every $4^{\text {th }}$ hourly for 72 hours and $8^{\text {th }}$ hourly from the $3^{\text {rd }}$ day. 
Table 1:

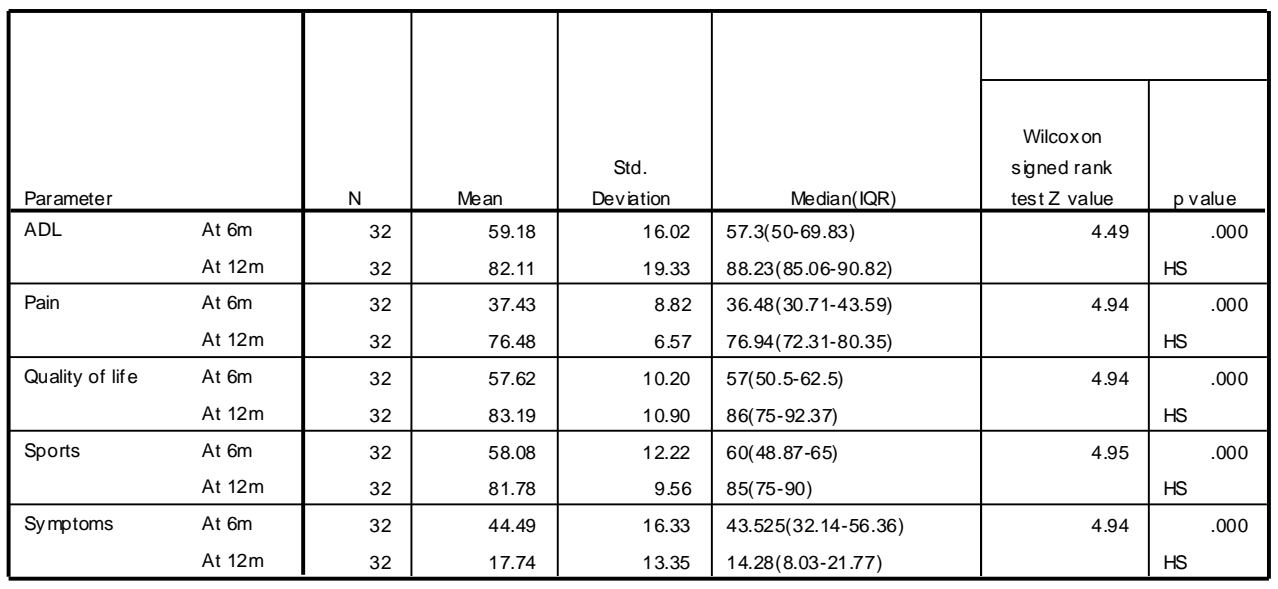

Table 2: MESS

\begin{tabular}{|c|c|c|c|c|}
\hline & Parameter & Pears on Correlation & $p$ & \\
\hline \multirow[t]{5}{*}{ At $6 \mathrm{~m}$} & ADL & .204 & .262 & \\
\hline & Pain & -.175 & .339 & \\
\hline & Quality of life & -.306 & .089 & \\
\hline & Sports & -.010 & .958 & \\
\hline & Symptoms & .053 & .775 & \\
\hline \multirow[t]{5}{*}{ At $12 \mathrm{~m}$} & ADL & .106 & .564 & \\
\hline & Pain & $-.403^{*}$ & .022 & sig \\
\hline & Quality of life & -.209 & .250 & \\
\hline & Sports & -.196 & .282 & \\
\hline & Sy mptoms & .202 & .268 & \\
\hline
\end{tabular}

*. Correlation is significant at the 0.05 level

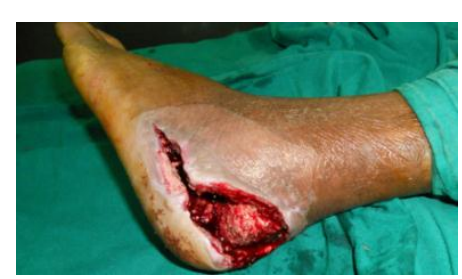

Fig. 1: Type 3B calcaneum fracture of left foot

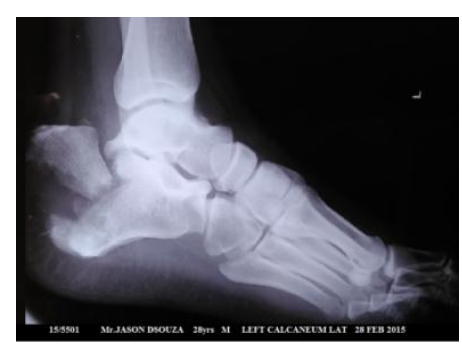

Fig. 2: Radiograph showing calcaneum fracture of left foot

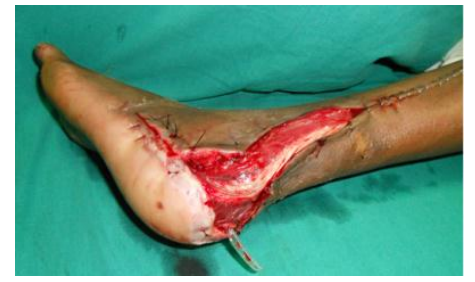

Fig 3: Peroneus brevis flap used for wound coverage

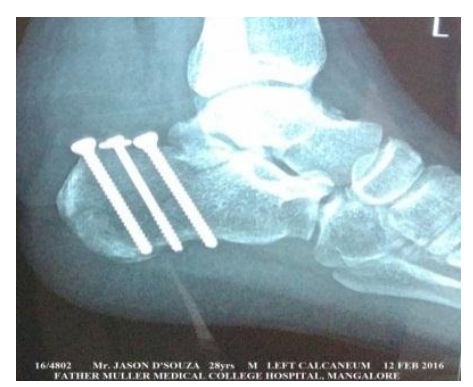

Fig.4: Radiograph showing united fracture of left calcaneum with implant in-situ after 1 year 


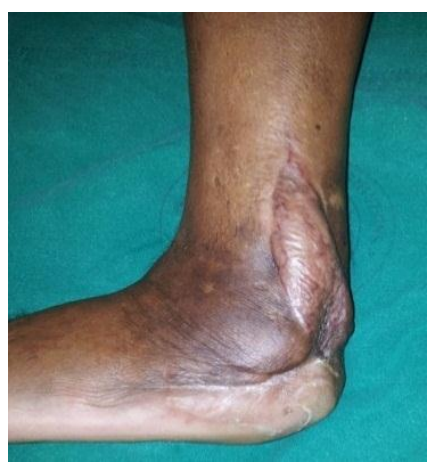

Fig. 5: 1 year follow up of Peroneus brevis flap

\section{Discussion}

Open fractures around the ankle and foot are complex fractures. It may be associated with dislocation and massive soft tissue defects.

Early surgery and soft tissue coverage has to be planned and executed by a surgeon who has immense experience in this area $^{1}$ as well as his ability to collaborate with a soft tissue surgeon for the best treatment outcome. However, principle states that if an injury of this type cannot be managed then provisional stabilization with ex-fix has to be done and patient shifted to a higher centre for further management. ${ }^{1}$

Based on our study, we would like to discuss the management of the open fractures under the following headings.

Timing of surgery is a critical aspect in reducing the bacterial load and attaining wound closure. In our study all patients underwent the initial wound debridement by a specialist within the first 12 hours following the trauma. The golden period of 6 hours could not be achieved in majority of the cases as operation theatre facility or specialist treatment was not available in rural areas. Most of the studies do not give any correlation between the initial debridement and post-procedure infection rate. However, few studies have stressed upon attaining a bony reduction and stabilization as early as possible to reduce complications of soft tissue compromise and delayed union., $^{2,3}$

Wound irrigation has a significant role to play in reducing the bacterial load and preventing infections of the bone. The standard protocol followed in type IIIB fractures is nine litres of normal saline given in pulsatile lavage. On the same context, studies have also proved that high pressure pulsatile lavage has deleterious effects on the soft tissue and transports the contaminants deep into the soft tissue. ${ }^{4,5}$ In our study we mixed $10 \%$ povidone iodine with $3 \%$ hydrogen peroxide followed by $0.9 \%$ normal saline wash which was repeated 3 times and the devitalized tissue was excised following this.

Fracture fixation has to be carried out immediately after the initial debridement. In our study, fracture is reduced and fixed with an external fixator. If a local flap is planned in the primary surgery, then an internal fixation using plates and screws are used to stabilize fractures. Early fracture fixation leads to shorter hospital stay, early rehabilitation, less joint stiffness. ${ }^{6}$ Only if adequate soft tissue coverage is not possible, we stabilized with external fixation. ${ }^{7}$ The important factors contributing to poor functional outcome are deep infection, bone loss, articular cartilage damage, post-op loss of reduction which alters joint mechanics causing osteoarthritis. $^{8}$

Antibiotic cover has been considered the standard of care since $1974^{9}$ when cephalosporins was used for an open fracture. A recent cochrane study showed that the admisinstration of antibiotics reduced the rate of infection by $59 \% .^{10}$ The timing of starting antibiotic coverage varies depending on the initial presentation to the hospital. The average time of administration in our study was 4 hours.

The protocol followed in our study was amikacin for 3 days, metrogyl for 10 days and ceftriaxonesulbactum combination for 6 days.

The old concepts of delayed wound closure once infection subsides have been phased out and now orthopedicians have started early closure if possible. ${ }^{11}$ If the wound coverage is delayed due to contamination or unavailability of microvascular surgery then vacuum assisted closure ${ }^{12}$ is used and a definitive procedure is undertaken when the wound is ready. There are multiple studies to substantiate that the outcome after early closure is superior to delayed closure. ${ }^{13,14}$ Skin grafts can be used to cover small skin defects on a vascular bed and free flaps are used to cover large defects. Local flaps are used in soft tissue destruction at the heel or ankle.

Complications commonly seen in free flaps are venous congestion and deep infection. However, in our study 1 patient had superficial wound infection which caused delayed wound healing. These cases were treated with intravenous antibiotics and daily dressing.

1 Latissmus dorsi free flap and anterolateral thigh flap failed due to venous congestion. In both the cases, flap was harvested and grafted on the $6^{\text {th }}$ day posttrauma. Delay in wound closure may have resulted in the failure due to patency of the blood vessels. Therefore the ideal time period according to our study is 3 days post trauma.

Every flap had a good functional outcome when compared to the opposite normal ankle and foot. No flap showed superiority. Hence based on the location and surgeon preference, adequate wound coverage using a flap is carried out.

Primary flap cover was not carried out if the wound was heavily contaminated, farm related injuries or delay in starting antibiotics. ${ }^{15}$

It's a disaster to amputate a salvageable limb. However a failed reconstruction leading to amputation is unforgiveable and frustrating to the patient. ${ }^{16,17}$ 


\section{Conclusion}

Specialized wound coverage techniques in the hands of an experienced surgeon gives a good functional outcome in type IIIB fractures of ankle and foot. The fracture has to be stabilized temporarily or fixed as early as possible. Mangled extremity severity score can predict the outcome of the fracture fixation and wound coverage. The selection of flaps depends on the surgeon preference and location of the wound. However, many patient related factors also plays a role in the best outcome of a flap. Timing of the wound coverage is an important aspect in reducing complications. The best time period is within 3 days of initial trauma.

Early mobilization once the wound has healed improves the range of movements of the joint and prevents stiffness. All methods of wound coverage showed equal functional outcome and no flap was superior to the other.

\section{References}

1. Orcutt S, Kilgus D, Ziner D (1988) the treatment of lowgrade open fractures without operative debridement. Read at the annual meeting of the orthopaedic trauma association, Dallas, TX, USA. Rajasekaran S. Ganga hospital open injury severity score - A score to prognosticate limb salvage and outcome measures in Type IIIb open tibial fractures. Indian J Orthop 2005;39:4-13.

2. Herscovici D Jr, Scaduto JM, Infante A (2007) Conservative treatment of isolated fractures of the medial malleolus. J Bone Joint Surg Br 89(1):89-93.

3. White CB, Turner NS, Lee GC, Haidukewych GJ (2003) Open ankle fractures in patients with diabetes mellitus. Clin Orthop Relat Res (414):37-44.

4. Boyd JI III, Wongworawat MD (2004) High-pressure pulsatile lavage causes soft tissue damage. Clin Orthop Relat Res 427:13-17.

5. Hassinger SM, Harding G, Wongworawat MD (2005) Highpressure pulsatile lavage propagates bacteria into soft tissue. Clin Orthop Relat Res 439:27-31.

6. Bray TJ, Endicott M, Capra SE (1989) Treatment of open ankle fractures. Immediate internal fixation versus closed immobilization and delayed fixation. Clin Orthop Relat Res (240):47-52.

7. White CB, Turner NS, Lee GC, Haidukewych GJ (2003) Open ankle fractures in patients with diabetes mellitus. Clin OrthopRelat Res (414):37-44.

8. Johnson EE, Davlin LB (1993) Open ankle fractures. The indications for immediate open reduction and internal fixation. Clin Orthop Relat Res (292):118-127.

9. Paul D (1973) Conservative and surgical therapy of open malleolar fractures. Zentralbl Chir 2, 98(44):1589-1593.

10. Gosselin RA, Roberts I, Gillespie WJ (2004) Antibiotics for preventing infection in open limb fractures. Cochrane Database Syst Rev 1:CD003764.

11. Rajasekaran S. Early versus delayed closure of open fractures. Injury. 2007;38:890-5.

12. Cross WW, Swiontkowski MF. Treatment principles in the management of open fractures. Indian Journal of Orthopaedics. 2008;42(4):377-386. doi:10.4103/00195413.43373

13. Cullen MC, Roy DR, Crawford AH. Open fractures of tibia in children. J Bone Joint Surg Am 1996;78:1039-4.
14. Davis AG, Erie MD. Primary closure of compound fracture wounds. J Bone Joint Surg Am 1948;30:40515 .

15. Rajasekaran S, Naresh Babu J, Dheenadhayalan J, et al. A score for predicting salvage and outcome in Gustilo type IIIA \& type IIIB open tibial fractures. JBJS (Br) 2006;88B(10):1351-60.

16. Bondurant FJ, Cotler HB, Buckle R, Miller-Crotchett $P$, Browner BD. The medical and economical impact of severely injured lower extremities. J Trauma 1988;28: 1270.

17. Hansen ST Jr. The Type-IIIC tibial fracture: salvage or amputation. J Bone Joint Surg [Am] 1987;69-A:799-800. 